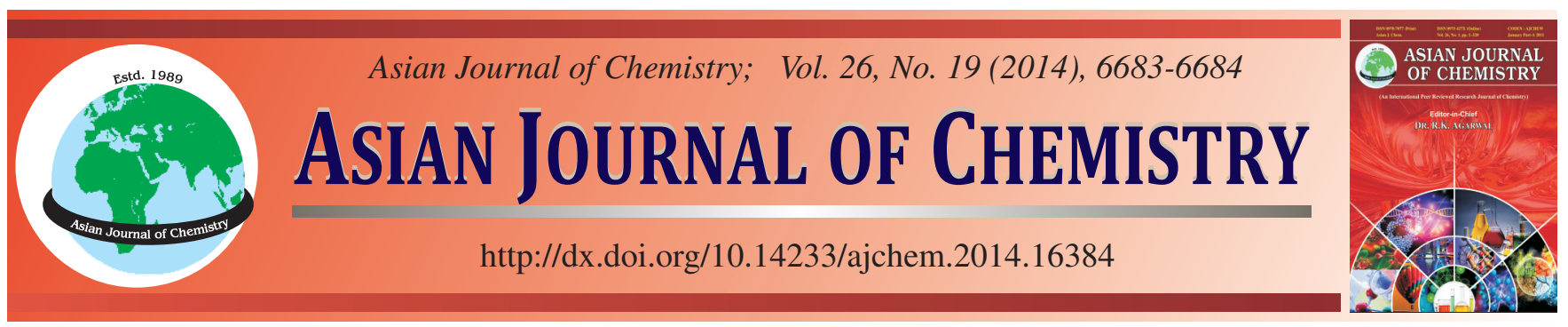

NOTE

\title{
GC-MS Analysis of Chemical Composition of the Essential Oil of Toona sinensis (A. Juss.) Roem Roots
}

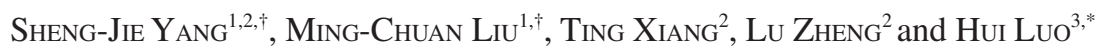

${ }^{1}$ Research Institute, SinpharTian-Li Pharmaceutical Co., Ltd, Hangzhou 311100, P.R. China

${ }^{2}$ Research Institute of Traditional Chinese Medicine, Yangtze River Pharmaceutical Group Co., Ltd, Taizhou 225321, P.R. China

${ }^{3}$ Guizhou Fruit Institute, Guizhou Academy of Agricultural Sciences, Guiyang 550006, P.R. China

*Corresponding author: Fax: +86 851 3762642; Tel: +86 13765104401; E-mail: luohui8732@163.com

$\dagger$ Both authors contributed equally to this work

Received: 17 September 2013;

Accepted: 14 March 2014;

Published online: 16 September 2014;

AJC-15987

The essential oil of Toonasinensis (A. Juss.) Roem roots, a traditional herbal medicine in China, was extracted by hydrodistillation and analyzed by gas chromatography coupled to mass spectrometry (GC-MS). Twenty compounds were identified. The essential oil yield and the percentage of identified compounds were 1.62 and $91.23 \%$, respectively. The major components were tridecane (15.54\%), tetradecane (7.00 \%), 9-octadecenoic acid, methyl ester (6.19\%), 13-docosenoic acid, methyl ester (5.13\%), (Z,Z)-9,12-octadecadienoic acid (4.53 $\%)$, 1-hexadecyne $(3.79 \%)$, and $\alpha$-cubebene $(3.07 \%)$. The study can provide quality control evidence and further exploitation of Toonasinensis (A. Juss.) Roem.

Keywords: Toonasinensis (A. Juss.) Roem, Essential oil, Hydrodistillation, Chemical composition.

For more than a decade, there has been a considerable interest in screening plant essential oils for medical use all over the world ${ }^{1}$. Essential oils are valuable natural products used as raw materials in many fields, such as perfumes, cosmetics, aromatherapy, spices, and nutrition ${ }^{2-4}$. Moreover, plant essential oils and their components have multiple and varied biological activities such as antitumor, antimicrobial, and antioxidant properties ${ }^{5-7}$.

Toona sinensis (A. Juss.) Roem is a species of Toona native to eastern and south eastern Asia, from North Korea south through most of eastern, central and south western China to Nepal, north eastern India, Myanmar, Thailand, Malaysia, and western Indonesia ${ }^{8}$. It is a deciduous tree growing to $25 \mathrm{~m}$ tall with a trunk up to $70 \mathrm{~cm}$ diameter. The leaves of $T$. sinensis (A. Juss.) Roem are a vegetable that has been very popular with vegetarians in China ${ }^{9}$. The tender leaves and stem have been used as a carminative and to treat enteritis, dysentery and itch in oriental medicine ${ }^{10}$. Also, its roots have been proved to inhibit tumor growth via induction of cancer cell apoptosis ${ }^{11}$. Previous phytochemical studies on T. sinensis (A. Juss.) Roem resulted in the identification ofretinoid, vitamins $\mathrm{B}$ and $\mathrm{C}$, $o$-coumaric acid, kaempferol, megallate, quercetin, afzelin, quercitrin, isoquercitrin and runtin ${ }^{12}$. Studies have also reported the chemical composition of the essential oils extracted from its tender leaves and seeds ${ }^{13-16}$. However, the composition of the essential oil of its roots remain unclear. In present work, the essential oil of $T$. sinensis (A. Juss.) Roem roots was extracted by hydrodistillation, and was analyzed by gas chromatography-mass spectrometry (GC-MS).

Fresh samples of $T$. sinensis (A. Juss.) Roem were collected from Bijie, Guizhou Province in China, in August 2011. Prof. Qingde Long, Department of Medicine, Guiyang Medical University, identified the plant material. A voucher specimen was deposited at Guiyang Medical University, Guiyang, China.

Extraction of essential oil: About $250 \mathrm{~g}$ of dried roots of T. sinensis (A. Juss.) Roem were cut into pieces, followed by hydrodistillation using a Clevenger-type apparatus for $5 \mathrm{~h}$. The essential oil was collected over water, dried over anhydrous sodium sulphate and stored at $4{ }^{\circ} \mathrm{C}$ until analyzed. The oil yield was about $1.62 \%$.

Gas chromatography-mass spectroscopy (GC-MS) analysis: A gas chromatographic-mass spectral analysis was performed on essential oil of T. sinensis (A. Juss.) Roem roots using an Agilent 6890 GC with Agilent 5973 mass selective detector (EI-MS, electron energy $=70 \mathrm{eV}$, scan range $=10$ $550 \mathrm{amu}$ ), and a fused silica capillary column (HP-5 ms, $30 \mathrm{~m}$ $\times 0.25 \mathrm{~mm})$ coated with $5 \%$ phenyl methyl siloxane $(0.25 \mu \mathrm{m}$ 
phase thickness). The carrier gas was helium (99.999\%) with a flow rate of $1 \mathrm{~mL} / \mathrm{min}$. The injector temperature was $250{ }^{\circ} \mathrm{C}$, and the oven temperature was programmed to initially hold for $2 \mathrm{~min}$ at $50{ }^{\circ} \mathrm{C}$, then ramp to $290^{\circ} \mathrm{C}$ at $5^{\circ} \mathrm{C} / \mathrm{min}$ for $2 \mathrm{~min}$. The interface temperature was $280^{\circ} \mathrm{C}$. A $1 \%$ (w/v) solution of each sample in dichloromethane was prepared, and $1 \mu \mathrm{L}$ was injected using a split injection technique with split ratio 20:1. The components were identified by comparison of their mass spectra with those of the NIST 5 mass spectra library.

The hydrodistillation of roots of $T$. sinensis (A. Juss.) Roem gave light yellowish oil with yield of $1.62 \%$. It is higher than reported for other plants industrially exploited as source of essential oils: lavender (0.8-1.8\%), mint (0.5-1\%), neroli (0.5-1\%), laurel (0.1-0.35\%) and Lippiarotundifolia $(0.01 \%)^{17}$. The identified constituents from the aerial parts of T. sinensis (A. Juss.) Roem, their retention data and chemical composition are presented in Table-1. All the compounds are arranged in order of their elution from the HP5-MS column. Twenty compounds have been identified representing around $91.23 \%$ of the total oil. The major component was dodecane (27.95\%), other components present in appreciable contents being: tridecane (15.54\%), tetradecane (7\%), 9-octadecenoic acid, methyl ester $(6.19 \%)$, 13-docosenoic acid, methyl ester (5.13\%), (Z,Z)-9,12-octadecadienoic acid (4.53\%), 1-hexadecyne $(3.79 \%)$, and $\alpha$-cubebene (3.07\%).

\begin{tabular}{clcc}
\multicolumn{4}{c}{ TABLE-1 } \\
\multicolumn{4}{c}{ CHEMICAL COMPONENTS OF ESSENTIAL } \\
\hline \multicolumn{3}{c}{ OIL OF T.sinensis (A. Juss.) ROEM ROOTS } \\
\hline No. & Compounds & $\begin{array}{c}\text { Retention } \\
\text { Time }\end{array}$ & Area (\%) \\
\hline 1 & Nonadecane & 4.09 & 2.73 \\
2 & Dodecane & 4.21 & 27.95 \\
3 & Tridecane & 5.04 & 15.54 \\
4 & Q-Cubebene & 5.61 & 3.07 \\
5 & Tetradecane & 5.89 & 7.00 \\
6 & (-)-Isoledene & 6.17 & 1.20 \\
7 & Pentadecane & 6.72 & 1.54 \\
8 & B-Neoclovene & 6.87 & 0.67 \\
9 & Calamenene & 7.06 & 1.75 \\
10 & Pentadecanoic acid, 14-methyl-, & 9.78 & 1.45 \\
& methyl ester & & \\
11 & Hexadecanoic acid, methyl ester & 9.85 & 1.53 \\
12 & n-Hexadecanoic acid & 10.05 & 1.16 \\
13 & (E,E)-9,12-Octadecadienoic acid, & 10.85 & 1.98 \\
& methyl ester & & \\
14 & 9-Octadecenoic acid, methyl ester & 10.88 & 6.19 \\
15 & Octadecanoic acid, methyl ester & 11.00 & 0.64 \\
16 & (Z,Z)-9,12-Octadecadienoic acid & 11.05 & 4.53 \\
17 & 11-Eicosenoic acid, methyl ester & 11.91 & 0.84 \\
18 & 1-Hexadecyne & 12.20 & 3.79 \\
19 & 13-Docosenoic acid, methyl ester & 13.09 & 5.13 \\
20 & 9,17-Octadecadienal & 15.57 & 2.54 \\
\hline & & & \\
& & &
\end{tabular}

Intense studies on essential oil composition of its seeds and leaves have been already published. Chen et al. ${ }^{13}$ studied the composition of essential oil extracted from $T$. sinensis (A. Juss.) leaves by steam distillation, with caryophyllene (24.75 $\%$ ), caryophyllene oxide (9.22\%), linalool (6.27\%), eudesma4(14),11-diene (5.92\%), and palmitoleic acid (5.58\%) as the main components. The essential oil of its seeds were also extracted, and its components were characterized by high percentages of trans-caryophvllene (11.45\%), $\gamma$-elemene (7.28 $\%)$, elemene (6.94\%), $\alpha$-longipinene $(6.46 \%)$, and calarene $(5.52 \%)^{15}$. The essential oil composition determined in our study was different from that of the essential oil of $T$. sinensis (A. Juss.) Roem leaves and seeds. Aliphatic hydrocarbons were the dominant class of compounds, instead of sesquiterpenes. However, some terpenoids were also found in the essential oil of $T$. sinensis (A. Juss.) Roem roots, such as $\alpha$-cubebene $(3.07 \%)$, (-)-isoledene $(1.20 \%), \beta$-neoclovene $(0.67 \%)$, calamenene $(1.75 \%)$ and so on.

\section{Conclusion}

The aim of this study was to describe the chemical composition of essential oil of $T$. sinensis (A. Juss.) Roem roots. The essential oil, obtained from roots by hydrodistillation, was analyzed by gas chromatography-mass spectrometry (GCMS). Twenty compounds were identified and the yield of essential oil was $1.62 \%$. The total identified compounds accounted for $91.23 \%$ of the oil, with tridecane (15.54\%), tetradecane $(7.00 \%)$, 9-octadecenoic acid, methyl ester (6.19\%), 13-docosenoic acid, methyl ester (5.13\%), (Z,Z)-9,12octadecadienoic acid (4.53\%), 1-hexadecyne (3.79\%), and $\alpha$-cubebene (3.07\%), comprising the main portion of the oil.

\section{ACKNOWLEDGEMENTS}

The authors thank the Science and Technology Major Specialized Projects for Significant New Drugs Creation of the $12^{\text {th }}$ Five-Year Plan (2012ZX09101231-004) and the Scientific Research of Guizhou (No.20126006) for the financial support.

\section{REFERENCES}

1. J. Lin, J. Dou, J. Xu and H.A. Aisa, Molecules, 17, 5030 (2012).

2. E. Derwich, R. Chabir, R. Taouil and O. Senhaji, Int. J. Pharm. Sci. Drug Res., 3, 130 (2011)

3. R. Priya, A. Prathapan, K.G. Raghu and A.N. Menon, Asian Pac. J. Trop. Biomed., 2, S695 (2012).

4. G. Innocenti, S. Dall'Acqua, G. Scialino, E. Banfi, S. Sosa, K. Gurung, M. Barbera and M. Carrara, Molecules, 15, 2326 (2010).

5. M. Saxena, J. Saxena, R. Nema, D. Singh and A. Gupta, J. Pharmacogn. Phytochem., 1, 168 (2012).

6. R.K. Upadhyay, P. Dwivedi and S. Ahmad, Asian J. Med. Sci., 2, 152 (2010).

7. S.A. Fayed, Res. J. Agric. Biol. Sci., 5, 740 (2009).

8. Y.L. Sun, W.G. Park, H.B. Lee, H.M. Kang and S.K. Hong, J. Biotechnol. Sci., 1, 76 (2013).

9. C.M. Chen, C.Y. Lin, L.C. Lin and T.C. Wan, Afr. J. Biotechnol., 11, 13831 (2012).

10. J.W. Liao, C.K. Hsu, M.F. Wang, W.M. Hsu and Y.C. Chan, Br. J. Nutr., 96, 400 (2006).

11. H.C. Chang, W.C. Hung, M.S. Huang and H.K. Hsu, Am. J. Chin. Med., 30, 307 (2002).

12. Q. Lin, M. Li, R. Zhou and Y. Liu, Afr. J. Biotechnol., 11, 1789 (2012).

13. C. Chen and K. Huang, Biomass Chem. Eng., 42, 27 (2008).

14. X. Liu, C. Zhang, A. Yu, Z. Tan and Y. Liu, Fine Chem., 25, 41 (2008).

15. Z. Liu, T.B. Ma and L.M. Sun, Chin. Pharm. J., 37, 94 (2002).

16. C. Wang, L. Gao, C. Liu, L. Li and Y. Li, Food Mach., 23, 83 (2007).

17. E. Derwich, Z. Benziane and R. Taouil, Chem. Bull. "POLITEHNICA, Univ. (Timisoara), 55, 103 (2010). 